\title{
Urological anomalies in anorectal malformations in The Netherlands: effects of screening all patients on long-term outcome
}

\author{
W. J. H. Goossens • I. de Blaauw • M. H. Wijnen • \\ R. P. E. de Gier - B. Kortmann - W. F. J. Feitz
}

Published online: 30 July 2011

(c) The Author(s) 2011. This article is published with open access at Springerlink.com

\begin{abstract}
Introduction Urological anomalies are frequently seen in patients with anorectal malformations (ARM) and can result in upper urinary tract deterioration. Whether the current method of screening is valid, adequate and needed for all patients is not clear. We, therefore, evaluated the urological screening methods in our ARM patients for changes in urological treatment, outcome and follow-up. Methods The medical records of 331 children born with an ARM in the period 1983-2003 were retrospectively studied. Documentation of diagnosis, screening method, urological anomalies, treatment, complications, follow-up and outcome were measured.

Results The overall incidence of urological anomalies was $52 \%$. The incidence of urological anomalies and urological follow-up time decreased with diminishing complexity of the ARM. Hydronephrosis, vesico-urethral reflux, lower urinary tract dysfunction and urinary incontinence were encountered most. Treatment invasiveness increased with the increase of complexity of an ARM. Lower urinary tract dysfunction needing urological care occurred in $43 \%$ in combination with lumbosacral or spinal
\end{abstract}

W. J. H. Goossens - R. P. E. de Gier - B. Kortmann ·

W. F. J. Feitz $(\bowtie)$

Department of Urology, Radboud University Nijmegen Medical Center, Nijmegen, The Netherlands

e-mail: w.feitz@uro.umcn.nl

I. de Blaauw · M. H. Wijnen

Department of Surgery/Pediatric Surgery, Radboud University

Nijmegen Medical Center, Nijmegen, The Netherlands

I. de Blaauw

Department of Pediatric Surgery, Erasmus MC, Sophia

Children's Hospital, Rotterdam, The Netherlands cord anomalies and in $8 \%$ with no abnormalities in the lumbosacral-/spinal region.

Conclusions Urological anomalies in patients with complex ARM are more severe than in patients with less complex ARM. Ultrasonography of the urinary tract should be performed in all patients. Voiding cysto-urethrography can be reserved for patients with dilated upper urinary tracts, urinary tract infections or lumbosacral and spinal abnormalities. All patients with complex ARM need urodynamic investigations. When using these indications, the screening for urological anomalies in ARM patients can be optimized with long-term follow-up in selected patients.

Keywords Anorectal malformation - Urological anomaly · VACTERL · Ultrasonography ·

Voiding cysto-urethrography · Urodynamic investigation

\section{Introduction}

Anorectal malformations (ARM) are congenital anomalies of the anorectum which cover a wide spectrum of anatomical anomalies, characterized by an absence of a normally formed anus at its normal position within the perineum [1, 2]. ARM range from complex anomalies of the hindgut and urogenital organs, such as a cloaca, to less complex perineal fistulas or vestibular fistulas [1]. It is well known that children with ARM show a high incidence of associated anomalies in other organ systems, which often have a high morbidity and mortality by themselves [3-6]. The overall incidence of these associated anomalies is more than $60 \%$ [7]. Urological anomalies are frequently seen in patients with ARM and can result in severe deterioration of the upper urinary tract when treated inadequately [1, 8-11]. An attempt to detect urological 
anomalies is necessary, as a lack of early measurements can lead to significant damage to the upper urinary tract [12-14]. Previous studies recommended that all children with ARM should undergo an ultrasonography of the urinary tract in the neonatal period $[8,12]$. To detect vesicoureteral reflux, all patients with a dilatation of the upper urinary tract should undergo a voiding cysto-urethrography $[8,12]$. Furthermore, sacral X-ray and an ultrasonography of the spinal cord should be made to detect lumbosacral anomalies or defects of the spinal cord [13, 15]. Patients with ARM and a coexisting anomaly of the lumbosacral spinal column or spinal cord are more likely to have lower urinary tract dysfunction. However, whether screening for urological anomalies in all patients with ARM improves urological treatment and outcome has not been investigated. The necessity of screening the whole spectrum and whole population of ARM patients is unclear. The urological anomalies found with the current screening methods may not have influenced treatment and outcome in the less complex cases. This study aimed to study the incidence of urologic anomalies associated with ARM and the relationship between the severity of the ARM and the incidence of these urological defects with a long-term outcome evaluation. Urologic follow-up, treatment and outcome are studied to test whether there is a difference in treatment regime between the various groups of ARM patients. Based on these data, recommendations are formulated regarding the screening for urological anomalies in patients with ARM.

\section{Materials and methods}

\section{Patients}

A retrospective evaluation of the medical records was performed for all children with ARM, referred to the department of pediatric surgery of the Radboud University Nijmegen Medical Center from 1983 to 2003. Within this period 351 patients were seen with this diagnosis, of which 20 were excluded due to insufficient or incomplete data, resulting in a cohort of 331 patients. In the medical records, patients were mostly classified according to the Wingspread classification. However, recently the Krickenbeck classification is accepted and most used to describe and classify ARM. For the present study the Krickenbeck classification was used and our patients were re-classified accordingly. We further divided our patients in complex malformations and less complex malformations. We defined the ARM as complex malformations when the medical record mentioned cloacal malformations, bladder fistulas, urethral fistulas (prostatic and bulbar), vaginal fistulas or no fistula. We considered them less complex malformations when there was mentioning of perineal fistulas or anterior displaced anus, vestibular fistulas or anal stenosis. Rectal atresias were also considered as less complex ARM as these malformations have similar good outcomes as perineal- or vestibular fistulas. The urological records of the patients who were also seen by a pediatric urologist were reviewed as well. These files included screening results of clinical examination and additional investigations to trace urologic anomalies, including treatment and follow-up time. Different treatment options were taken together and grouped into modalities of increasing invasiveness (expectative, conservative measurements, medication and surgery).

\section{Statistical analysis}

Statistical analysis was done using SPSS 16.0. The incidence and treatment of the different urological anomalies were analyzed using the Chi-Square Test and Fisher's Exact Test. The statistical calculations of the follow-up time were done with the One-way ANOVA Test. A $p$ value $<0.05$ was considered to be statistically significant.

\section{Results}

Three hundred thirty-one patients with ARM were evaluated of which $48 \%$ were female and $52 \%$ were male. The patients had a variety in the severity of ARM (Table 1). In one female and one male patient the type of ARM was unclassified. These patients were not taken into evaluation during the rest of the study. Forty-six percent of male patients and $17 \%$ of female patients had a complex ARM. Urological anomalies were found in 172 cases (52\%). The incidence of urological anomalies decreased with decreasing complexity of the ARM (Table 1). Remarkably, rectal atresias, which are considered less complex malformations with good prognosis had a high incidence of urological anomalies. Urological follow-up time ranged from 48 months for the youngest, to 300 months for the oldest patients. Mean follow-up time in the entire group was 40 months and decreased with decreasing severity of ARM (Table 1). The four most seen urological anomalies in patients with ARM were hydronephrosis, vesico-ureteral reflux, lower urinary tract dysfunction and urinary incontinence with a total incidence of 24,18 , 14 and $12 \%$, respectively. In all four anomalies, the incidence of the urological anomalies diminished with decreasing complexity of ARM (Tables 2, 3).

Treatment of urological anomalies in ARM

Treatment of hydronephrosis is similar in patients with complex and less complex ARM (Table 4). Antibiotic 
Table 1 Cohort characteristics

\begin{tabular}{lcccc}
\hline & \multicolumn{1}{l}{ Sex } & & $\begin{array}{l}\text { Mean urological } \\
\text { follow-up time } \\
\text { (months) }\end{array}$ \\
\cline { 2 - 4 } & $\begin{array}{l}\text { Total } \\
N(\%)\end{array}$ & $\begin{array}{l}\text { Female } \\
N(\%)\end{array}$ & $\begin{array}{l}\text { Male } \\
N(\%)\end{array}$ & \\
\hline Cloaca & $13(4)$ & $13(100)$ & $0(0)$ & 147 \\
Bladder neck fistula & $4(1)$ & $0(0)$ & $4(100)$ & 119 \\
Vaginal fistula & $5(2)$ & $5(100)$ & $0(0)$ & 45 \\
Urethral fistula (prostatic and bulbar) & $57(17)$ & $0(0)$ & $57(100)$ & 79 \\
No fistula & $26(8)$ & $9(35)$ & $17(66)$ & 38 \\
Rectal atresia & $7(2)$ & $1(14)$ & $6(86)$ & 57 \\
Vestibular fistula & $40(12)$ & $40(100)$ & $0(0)$ & 27 \\
Perineal fistula (including & $164(50)$ & $87(53)$ & $77(47)$ & 22 \\
anterior displaced anus) & & & & \\
Anal stenosis & $13(4)$ & $4(31)$ & $9(69)$ & 9 \\
Unknown & $2(1)$ & $1(50)$ & $1(50)$ & 0 \\
Total & $331(100)$ & $160(48)$ & $171(52)$ & 40 \\
\hline
\end{tabular}

Table 2 Incidence of most common urological anomalies in complex ARM

\begin{tabular}{|c|c|c|c|c|c|}
\hline & \multicolumn{5}{|c|}{ Type of anorectal malformation } \\
\hline & $\begin{array}{l}\text { Cloaca } \\
(n=13) \\
N(\%)\end{array}$ & $\begin{array}{l}\text { Bladder neck fistula } \\
(n=4) \\
N(\%)\end{array}$ & $\begin{array}{l}\text { Vaginal fistula } \\
(n=5) \\
N(\%)\end{array}$ & $\begin{array}{l}\text { Urethral fistula }^{\mathrm{a}} \\
(n=57) \\
N(\%)\end{array}$ & $\begin{array}{l}\text { No fistula } \\
(n=26) \\
N(\%)\end{array}$ \\
\hline Hydronephrosis & $8(62)$ & $1(25)$ & $0(0)$ & $26(46)$ & $8(31)$ \\
\hline Vesico-ureteral reflux & $7(54)$ & $1(25)$ & $2(40)$ & $19(33)$ & $4(15)$ \\
\hline Lower urinary tract dysfunction & $10(77)$ & $2(50)$ & $0(0)$ & $14(25)$ & $2(8)$ \\
\hline Urinary incontinence & $6(46)$ & $1(25)$ & $1(20)$ & $14(25)$ & $1(4)$ \\
\hline
\end{tabular}

${ }^{a}$ Urethral fistula: prostatic- and bulbar fistulas

Table 3 Incidence of most common urological anomalies in less complex ARM

\begin{tabular}{|c|c|c|c|c|}
\hline & \multicolumn{4}{|c|}{ Type of anorectal malformation } \\
\hline & $\begin{array}{l}\text { Rectal atresia } \\
(n=7) \\
N(\%)\end{array}$ & $\begin{array}{l}\text { Vestibular fistula } \\
(n=40) \\
N(\%)\end{array}$ & $\begin{array}{l}\text { Perineal fistula } \\
(n=164) \\
N(\%)\end{array}$ & $\begin{array}{l}\text { Anal stenosis } \\
(n=13) \\
N(\%)\end{array}$ \\
\hline Hydronephrosis & $2(29)$ & $7(18)$ & $25(15)$ & $2(15)$ \\
\hline Vesico-ureteral reflux & $0(0)$ & $8(20)$ & $19(12)$ & $1(8)$ \\
\hline Lower urinary tract dysfunction & $0(0)$ & $4(10)$ & $14(9)$ & $1(8)$ \\
\hline Urinary incontinence & $1(14)$ & $2(5)$ & $11(7)$ & $2(15)$ \\
\hline
\end{tabular}

prophylaxis was given in 53\% of the patients with hydronephrosis in the complex ARM group, compared to $36 \%$ in the less complex group. The number of patients receiving surgical treatment was practically equal. Reimplantations of ureters were performed in three patients with complex ARMs and two patients with less complex ARMs. A pyeloplasty was done in one patient in both groups. A nephrectomy was performed in two patients with a complex ARM. Vesicostomy or uretero-cutaneostomy was performed in two patients with a complex ARM and three patients in the less complex ARM group. Treatment of vesico-ureteral reflux also was comparable in both groups (Table 5). The two patients with less complex ARM and reflux underwent a reimplantation of the ureter. In the complex ARM group, reimplantation of the ureter was performed in six cases, two patients required a nephroureterectomy, and one patient got a vesicostomy.

In patients with lower urinary tract dysfunction, surgery was exclusively performed in patients with complex ARM (Table 6). Of these 11 patients, 3 underwent an 
Table 4 Treatment of hydronephrosis in ARM

* Complex ARM versus less complex ARM: $p=0.189$

Table 5 Treatment of vesicoureteral reflux in ARM

* Complex ARM versus less complex ARM: $p=0.202$

\begin{tabular}{lllll}
\hline & Treatment & & & \\
\cline { 2 - 5 } & Expectative & AB-prophylaxis & Surgery & Total* \\
\hline Complex ARM, $N(\%)$ & $12(31 \%)$ & $23(53 \%)$ & $8(19 \%)$ & $43(100 \%)$ \\
Less complex ARM, $N(\%)$ & $17(47 \%)$ & $13(36 \%)$ & $6(17 \%)$ & $36(100 \%)$ \\
Total ARM, $N(\%)$ & $29(37 \%)$ & $36(46 \%)$ & $14(18 \%)$ & $79(100 \%)$ \\
\hline
\end{tabular}

\begin{tabular}{llllll}
\hline & \multicolumn{2}{l}{ Treatment } & & \\
\cline { 2 - 6 } & Expectative & AB-prophylaxis & Deflux injections & Surgery & Total* \\
\hline Complex ARM, $N(\%)$ & $2(6 \%)$ & $20(60 \%)$ & $2(6 \%)$ & $9(27 \%)$ & $33(100 \%)$ \\
Less complex ARM, $N(\%)$ & $1(4 \%)$ & $23(82 \%)$ & $2(7 \%)$ & $2(7 \%)$ & $28(100 \%)$ \\
Total ARM, $N(\%)$ & $3(5 \%)$ & $43(72 \%)$ & $4(7 \%)$ & $11(18 \%)$ & $60(100 \%)$ \\
\hline
\end{tabular}

Table 6 Treatment of lower urinary tract dysfunction

\begin{tabular}{|c|c|c|c|c|c|c|}
\hline & \multicolumn{6}{|l|}{ Treatment } \\
\hline & Expectative & $\begin{array}{l}\text { Conservative } \\
\text { measurements }\end{array}$ & $\begin{array}{l}\text { Anticholinergic } \\
\text { medication }\end{array}$ & $\begin{array}{l}\text { Clean intermittent } \\
\text { catheterization }\end{array}$ & Surgery & Total* \\
\hline Complex ARM, $N(\%)$ & $1(4 \%)$ & $1(4 \%)$ & $9(32 \%)$ & $6(21 \%)$ & $11(39 \%)$ & $28(100 \%)$ \\
\hline Less complex ARM, $N(\%)$ & $4(22 \%)$ & $1(6 \%)$ & $9(50 \%)$ & $4(22 \%)$ & $0(0 \%)$ & $18(100 \%)$ \\
\hline Total ARM, $N(\%)$ & $5(11 \%)$ & $2(4 \%)$ & $18(39 \%)$ & $10(22 \%)$ & $11(24 \%)$ & $46(100 \%)$ \\
\hline
\end{tabular}

* Complex ARM versus less complex ARM: $p<0.05$

augmentation of the bladder, 5 needed a vesicostomy and 3 received a Bricker urinary deviation. The amount of patients needing clean intermittent catheterization was the same in the complex and less complex group. Anticholinergic medication was prescribed in $50 \%$ of the patients with less complex ARMs, compared to $32 \%$ in the complex ARM group. In the complex ARM group 35\% of the patients needed surgical intervention to treat urinary incontinence compared to $6 \%$ of the patients with less complex ARM (Table 7). One patient in the less complex ARM group was treated by a reconstruction of the bladder neck. Of the patients receiving surgery in the complex ARM group, four patients received a Bricker urinary deviation, three patients received a vesicostomy, and in one patient a reconstruction of the bladder neck was performed.

Lumbosacral-/spinal cord anomalies and lower urinary tract dysfunction in ARM

The incidence of anomalies of the lumbosacral spine and spinal cord defects are shown in Table 8. Of the patients with a complex ARM $39 \%$ also had a lumbosacral or spinal cord anomaly compared to $8 \%$ of the patients with a less complex ARM. Subsequently, $43 \%$ of the patients with a lumbosacral-/spinal cord anomaly associated with their
ARM suffer from lower urinary tract dysfunction (Table 9). However, $8 \%$ of the children without any anomaly of the lumbosacral spine or spinal cord also had lower urinary tract dysfunction.

\section{Discussion}

Urological anomalies are frequently seen in patients with ARM. This study aimed to evaluate the need of screening for urological anomalies in patients with ARM. We aimed to classify all ARMs according to fistula level (Krickenbeck International classification) [16]. However, as the Wingspread classification [17] was mostly used in the time period our patients were operated to determine the operative approach, data to classify the ARM according to fistula level were not always available. Due to insufficient data, it was impossible in urethral fistulas to distinguish between a prostatic fistula, a complex condition that is frequently accompanied by urological pathology, and bulbar fistula, a relatively less severe malformation with less urological problems [18]. We also know that a true vaginal fistula is a rare and previously overestimated malformation [19]. Thus, some of the vaginal fistulas in our series are also likely to have been vestibular fistulas, a less complex 
Table 7 Treatment of urinary incontinence in ARM

\begin{tabular}{|c|c|c|c|c|c|c|}
\hline & \multicolumn{6}{|l|}{ Treatment } \\
\hline & Expectative & $\begin{array}{l}\text { Conservative } \\
\text { measurements }\end{array}$ & $\begin{array}{l}\text { Anticholinergic } \\
\text { medication }\end{array}$ & $\begin{array}{l}\text { Collagen-injections } \\
\text { bladder neck }\end{array}$ & Surgery & Total* \\
\hline Complex ARM, $N(\%)$ & $1(4 \%)$ & $9(39 \%)$ & $4(17 \%)$ & $1(4 \%)$ & $8(35 \%)$ & $23(100 \%)$ \\
\hline Less complex ARM, $N(\%)$ & $0(0 \%)$ & $9(56 \%)$ & $6(38 \%)$ & $0(0 \%)$ & $1(6 \%)$ & $16(100 \%)$ \\
\hline Total ARM, $N(\%)$ & $1(3 \%)$ & $18(46 \%)$ & $10(26 \%)$ & $1(3 \%)$ & $9(23 \%)$ & $39(100 \%)$ \\
\hline
\end{tabular}

* Complex ARM versus less complex ARM: $p=0.146$

Table 8 Incidence of lumbosacral-/spinal cord anomalies in ARM

* Complex ARM versus Less Complex ARM, $p<0.001$

Table 9 Lumbosacral-/spinal cord anomalies and lower urinary tract dysfunction in $\operatorname{ARM}(p<0.001)$

* Lumbosacral or spinal cord anomaly present versus not present: $p<0.001$

\begin{tabular}{llll}
\hline & \multicolumn{4}{l}{ Lumbosacral-/spinal cord anomaly } & Total \\
\cline { 2 - 4 } & Yes* & \multicolumn{1}{l}{ No } & $105(32 \%)$ \\
\hline Complex ARM, $N(\%)$ & $41(39 \%)$ & $64(61 \%)$ & $224(68 \%)$ \\
Less complex ARM, $N(\%)$ & $19(8 \%)$ & $205(92 \%)$ & $329(100 \%)$ \\
Total, $N(\%)$ & $60(18 \%)$ & $269(82 \%)$ & \\
\hline
\end{tabular}

\begin{tabular}{llrr}
\hline & \multicolumn{4}{l}{ Lower urinary tract dysfunction } \\
\cline { 2 - 4 } & \multicolumn{1}{c}{ Yes* } & No* & Total \\
\hline \multicolumn{2}{l}{ Lumbosacral-/spinal cord anomaly } & & $60(18 \%)$ \\
Yes, $N(\%)$ & $26(43 \%)$ & $34(57 \%)$ & $269(82 \%)$ \\
No, $N(\%)$ & $21(8 \%)$ & $248(92 \%)$ & $329(100 \%)$ \\
Total, $N(\%)$ & $47(14 \%)$ & $282(86 \%)$ & \\
\hline
\end{tabular}

condition. For analytical purposes of our study, we grouped our patients into two categories: complex and less complex ARM. Because of the enormous variety in treatment options for the urological anomalies as well, different treatment options were grouped into modalities of increasing invasiveness (expectative, conservative measurements, medication and surgery).

More than $50 \%$ of the patients with an ARM within our cohort suffered from one or more associated urological anomalies. Most series show a similar incidence of 25-50\% [1, 4-6, 8-10, 14, 15, 20, 21]. The differences in these studies are mostly due to the fact that in some of these studies (as in our study) all urological anomalies were evaluated, whereas in other series not all anomalies are taken into the evaluation (e.g., cryptorchism). Furthermore, urological anomalies occur more frequently in complex forms of ARM. As our hospital is a referral centre for complex pediatric surgery, it might be that more complex cases are presented than in other patient cohorts (Fig. 1).

In general, patients with complex ARM more often suffer from severe urological anomalies than patients with less complex ARM. This is seen in the amount of invasive treatments these patients require. Hydronephrosis was encountered most $(24 \%)$. This corresponds well with data retrieved from other series [4-6, 10, 20]. The main difference in treatment of hydronephrosis in patients with complex and less complex ARM was found in the amount of patients receiving antibiotic prophylaxis. As patients with a complex ARM often have fistula between terminal rectum and urinary tract, hydronephrosis is mostly treated with antibiotic prophylaxis to prevent upper urinary tract infections. In less complex ARM, however, more often an expectative approach is chosen. This may be due to the fact that the risk of infection is considered to be lower because there is no fistula to the urinary tract but to the vestibulum or the perineum. The finding of hydronephrosis in patients with less complex ARM did not have many consequences for treatment. One could debate the need to screen every patient with ultrasonography of the urinary tract. However, hydronephrosis is an anomaly that can result from other additional uropathology (e.g., vesico-ureteral reflux) needing therapy. Furthermore, ultrasonography is noninvasive and it is a relatively easy way to detect other anomalies of the urinary tract. Therefore, we acknowledge the importance of ultrasonography of the urinary tract and recommend carrying it out it in all patients with ARM. 


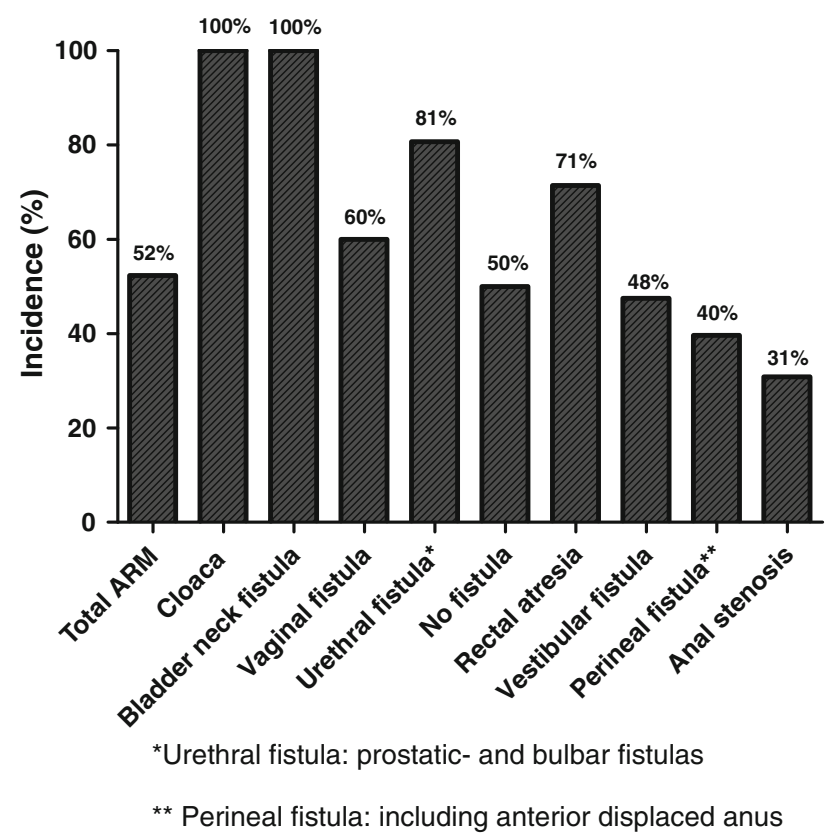

Fig. 1 Incidence of urological anomalies in ARM. Asterisk urethral fistula: prostatic- and bulbar fistulas, double asterisk perineal fistula: including anterior displaced anus

Vesico-ureteral reflux was seen in $18 \%$ of the patients, and a decreasing incidence was seen with decreasing severity of the ARM. Previous studies showed an incidence ranging from 14 to $27 \%[9,10,15,22]$. In our population, vesico-ureteral reflux was mostly encountered performing a voiding cysto-urethrography (VCUG). Because not all infants in the early part of this series received a VCUG, the true incidence may be underestimated. Most cases of vesico-ureteral reflux in our population were treated with a conservative approach using antibiotic prophylaxis. Only a small group of patients needed surgical intervention to prevent damage to the upper urinary tract. Patients with a complex ARM were more likely to have severe vesicoureteral reflux that qualifies for a surgical correction than children with less complex ARM. Nevertheless, this does not mean that patients with less complex ARM never had severe reflux. As severe vesico-ureteral reflux often goes hand in hand with dilatation of the upper urinary tract, we advise VCUG-evaluation in all patients with ARM who show a dilatation of the upper urinary tract on ultrasonography. Also, patients who have had a urinary tract infection should undergo VCUG-screening. This corresponds with recommendations made by others [4, 6, 8-10, 12].

Many patients with ARM have lower urinary tract dysfunction that causes clinically important urological problems such as incontinence and upper urinary tract deterioration $[1,12,13,15]$. Lower urinary tract dysfunction is defined as any functional anomaly of the bladder and/or urethra that has negative influence on voiding function. In patients with ARM, voiding dysfunction usually is neuropathic in origin and is commonly caused by associated defects of the lumbosacral spinal column (e.g., sacral agenesis) or abnormalities in the spinal cord (e.g., tethered spinal cord) $[13,15,23]$. Less commonly, iatrogenic pelvic nerve damage acquired during reconstruction of the ARM causes voiding dysfunction [2, 15, 24, 25].

Patients with complex ARM suffered significantly more often from lumbosacral-/spinal cord anomalies than patients with a less complex ARM. Moreover, patients with ARM and lumbosacral or spinal cord anomaly more often had lower urinary tract dysfunction, with voiding problems as a consequence. The designated diagnostic method to encounter lower urinary tract dysfunction is an urodynamic investigation. In the present study, urodynamic assessment was only performed in selected cases. Other groups have recommended urodynamic investigation in all patients with ARM that have sacral agenesis or a defect of the spinal cord $[12,15]$. According to their data only $2 \%$ of the children without lumbosacral-/spinal cord anomalies who have lower urinary tract dysfunction will be missed. However, according to our study, retrieved from a much larger population of patients with ARM, $8 \%$ of the patients without lumbosacral or spinal cord anomalies will have lower urinary tract dysfunction and will be missed following that recommendation. Lower urinary tract dysfunction has its highest incidence in complex ARM, has a tendency to be more severe in patients with complex ARM and it more frequently requires invasive treatment. We, therefore, recommend urodynamic screening of all patients with complex ARM. However, as patients with less complex ARM are not free of risk to develop lower urinary tract dysfunction, clinical follow-up of the miction pattern has to be done as soon as the patient reaches an age where full voiding control may be expected to encounter subclinical voiding problems.

In conclusion, urological anomalies in patients with complex ARM are more severe than in patients with less complex ARM. Ultrasonography of the urinary tract should be performed in all patients. Voiding cysto-urethrography can be reserved for patients with dilated upper urinary tracts, lumbosacral and spinal abnormalities, or in case of additional urinary tract infections. All patients with complex ARM need urodynamic investigations. When using these indications, the screening for urological anomalies in ARM patients can be optimized with long-term follow-up in selected patients.

Open Access This article is distributed under the terms of the Creative Commons Attribution Noncommercial License which permits any noncommercial use, distribution, and reproduction in any medium, provided the original author(s) and source are credited. 


\section{References}

1. Levitt MA, Pena A (2007) Anorectal malformations. Orphanet J Rare Dis 26(2):33

2. Pena A (1995) Anorectal malformations. Semin Pediatr Surg 4(1):35-47

3. Hassink EA, Rieu PN, Hamel BC, Severijnen RS, vd Staak FH, Festen C (1996) Additional congenital defects in anorectal malformations. Eur J Pediatr 155(6):477-482

4. Mittal A, Airon RK, Magu S, Rattan KN, Ratan SK (2004) Associated anomalies with anorectal malformation (ARM). Indian J Pediatr 71(6):509-514

5. Ratan SK, Rattan KN, Pandey RM, Mittal A, Magu S, Sodhi PK (2004) Associated congenital anomalies in patients with anorectal malformations-a need for developing a uniform practical approach. J Pediatr Surg 39(11):1706-1711

6. Stoll C, Alembik Y, Dott B, Roth MP (2007) Associated malformations in patients with anorectal anomalies. Eur J Med Genet 50(4):281-290

7. Rintala RJ (2009) Congenital anorectal malformations: anything new? J Pediatr Gastroenterol Nutr 48(Suppl 2):S79-S82

8. Boemers TM, de Jong TP, van Gool JD, Bax KM (1996) Urologic problems in anorectal malformations. Part 2: functional urologic sequelae. J Pediatr Surg 31(5):634-637

9. McLorie GA, Sheldon CA, Fleisher M, Churchill BM (1987) The genitourinary system in patients with imperforate anus. J Pediatr Surg 22(12):1100-1104

10. Rich MA, Brock WA, Pena A (1988) Spectrum of genitourinary malformations in patients with imperforate anus. Pediatr Surg Int 2-3:110-113

11. Wiener ES, Kiesewetter WB (1973) Urologic abnormalities associated with imperforate anus. J Pediatr Surg 8(2):151-157

12. Boemers TM, Beek FJ, Bax NM (1999) Review. Guidelines for the urological screening and initial management of lower urinary tract dysfunction in children with anorectal malformations- the ARGUS protocol. BJU Int 83(6):662-671

13. Jindal B, Grover VP, Bhatnagar V (2009) The assessment of lower urinary tract function in children with anorectal malformations before and after PSARP. Eur J Pediatr Surg 19(1):34-37
14. Parrott TS (1977) Urologic implications of imperforate anus. Urology 10(5):407-413

15. Boemers TM, Beek FJ, van Gool JD, de Jong TP, Bax KM (1996) Urologic problems in anorectal malformations. Part 1: Urodynamic findings and significance of sacral anomalies. J Pediatr Surg 31(3):407-410

16. Holschneider A, Hutson J, Pena A, Beket E, Chatterjee S, Coran A et al (2005) Preliminary report on the International Conference for the Development of Standards for the Treatment of Anorectal Malformations. J Pediatr Surg 40(10):1521-1526

17. Stephens FD, Smith ED (1986) Classification, identification, and assessment of surgical treatment of anorectal anomalies. Pediat Surg Int 1(4):200-205

18. Pena A, Hong A (2000) Advances in the management of anorectal malformations. Am J Surg 180(5):370-376

19. Rosen NG, Hong AR, Soffer SZ, Rodriguez G, Pena A (2002) Rectovaginal fistula: a common diagnostic error with significant consequences in girls with anorectal malformations. J Pediatr Surg 37(7):961-965

20. Belman AB, King LR (1972) Urinary tract abnormalities associated with imperforate anus. J Urol 108(5):823-824

21. Puchner PJ, Santulli TV, Lattimer JK (1975) Urologic problems associated with imperforate anus. Urology 6(2):205-208

22. Senel E, Akbiyik F, Atayurt H, Tiryaki HT (2010) Urological problems or fecal continence during long-term follow-up of patients with anorectal malformation. Pediatr Surg Int 26(7):683-689

23. Levitt MA, Patel M, Rodriguez G, Gaylin DS, Pena A (1997) The tethered spinal cord in patients with anorectal malformations. J Pediatr Surg 32(3):462-468

24. Hong AR, Acuna MF, Pena A, Chaves L, Rodriguez G (2002) Urologic injuries associated with repair of anorectal malformations in male patients. J Pediatr Surg 37(3):339-344

25. Warne SA, Godley ML, Wilcox DT (2004) Surgical reconstruction of cloacal malformation can alter bladder function: a comparative study with anorectal anomalies. J Urol 172(6 Pt 1):2377-2381 